\title{
Retrospective Analysis of Complications Associated with Laparoscopic Cholecystectomy for Symptomatic Gallstones
}

\author{
FNU Amreek ${ }^{1}$, Syed Zohaib Maroof Hussain ${ }^{2}$, Munawar H. Mnagi ${ }^{3}$, Amber Rizwan ${ }^{4}$ \\ 1. General Surgery, New York University Langone Medical Center, New York, USA 2. Surgery, Aga Khan University \\ Hospital, Karachi, PAK 3. General Surgery, Shaheed Mohtarma Benazir Bhutto Medical College Lyari, Karachi, PAK 4. \\ Family Medicine, Dr. Ruth Pfau Hospital, Karachi, PAK
}

Corresponding author: Amber Rizwan, amber_aljazeera109@hotmail.com

\section{Abstract}

\section{Introduction}

Gallstones are the major cause of global morbidity. Laparoscopic approach has well-established advantages as compared to the conventional open procedure. It promises better recovery, lower morbidity, and lower postoperative pain, shortens the duration of hospital stay, and has a lower mortality rate. The aim of this study is to assess the frequency of complications in laparoscopic cholecystectomies indicated for symptomatic gallstones and also evaluate the rate of conversion.

\section{Methods}

In this retrospective analysis, all records of laparoscopic cholecystectomy, in patients of age $\geqslant 18$ years, for symptomatic gallstones, from January 2015 till December 2018 in one of the largest public tertiary care hospitals in Pakistan were included.

\section{Results}

The rate of complications associated with laparoscopic cholecystectomy was $6.8 \%$. Older age, obesity, and multiple pre-operative risk factors were associated with complications. The most common intra-operative complication was hemorrhage (1.3\%) and most common postoperative complication was surgical site infection (2.7\%). Our conversion rate was 3.6\%. Both intra-operative and postoperative complications were more common in procedures which were converted to open.

\section{Conclusion}

The rate of complication and conversion to open in laparoscopic cholecystectomy is not very high. Older age, obesity, and multi-morbidity was associated with complications. Complicated procedures were more commonly needed to be converted to open.

Received 06/24/2019

Review began 06/24/2019

Review ended 07/07/2019

Published 07/16/2019

๑) Copyright 2019

Amreek et al. This is an open access

article distributed under the terms of the Creative Commons Attribution License CC-BY 3.0., which permits unrestricted use, distribution, and reproduction in any medium, provided the original author and source are credited.

Categories: General Surgery

Keywords: laparoscopic cholecystectomy, gallstones, conversion to open, retrospective, pakistan, complication rate, mortality rate

\section{Introduction}

Gallstones disease has been a major cause of global morbidity with varying degree of prevalence based on the geographical, racial, and ethnic parameters. Gallstones are at least three to four times more common in females. The incidence of gallstones increases with advancing age and are rare before 20 years of age [1]. In the United States (US), $15 \%$ of the adult population has gall bladder stones [2]. In Pakistan, the prevalence of gallstones has been reported to be $10 \%$ [3]. Higher incidence may be explained by the obesity epidemic and sedentary lifestyles [2].

Laparoscopic cholecystectomy (LC) was first introduced in the mid-1980s for symptomatic gallstones. Currently, it is the gold standard treatment for symptomatic gallstones [4]. In the initial decades, laparoscopic procedures were only restricted for well-experienced senior surgeons, however, studies gradually showed how the level of surgical expertise and the duration of practice did not impact the patient outcome in laparoscopic procedures. LC is a safe procedure commonly performed by surgical residents under the supervision of there attending [5]. Good procedure outcome and the reduced in-hospital stay have aided the dramatic shift from open to laparoscopic approach to gallstones. More than $90 \%$ of the 830,000 cholecystectomy in the US are performed using a laparoscopic approach [6]. 
pain, shortened duration of hospital stay, and lower mortality rate. However, intraoperative bleeding was seen to be unaffected by the selection of operative technique [7]. The incidence of major complications with LC remains as low as 5\% [8]. There may be several factors contributing to the risk of conversion to an open procedure. Distorted anatomy, excessive bleeding, visceral injury, adhesion, equipment failure and surgeons expertise are all factors that increase conversion from LC to open approach [9]. The frequency of conversion has been reported to be $5 \%$ [10]. The aim of this study is to assess the frequency of complications in LC indicated for symptomatic gallstones and rates of conversion from laparoscopic to conventional open cholecystectomy.

\section{Materials And Methods}

In this retrospective analysis, all patient records of laparoscopic cholecystectomy from January 2015 till December 2018 were included. The study was conducted in one of the largest public tertiary care hospitals in Sind, Pakistan. The study was approved by the institutional review board.

All records were of patients of age $\geqslant 18$ years of both genders. All records were of patients who were admitted from the outpatient department with symptomatic gallstones. Other conditions such as choledocholithiasis or dilated common bile duct ( $\mathrm{CBD}>8 \mathrm{~mm}$ in diameter), acute cholecystitis, malignancy or mass at porta hepatis, and history of jaundice and/or previous abdominal or pelvic surgery were excluded from the analysis.

All data was entered and analyzed using SPSS for Windows version 23.0 (IBM Corp., NY, USA). Mean and the standard deviation was calculated for continuous variables. Frequencies and percentages were calculated for continuous variables. The correlation analysis was done for characteristics of patients with and without complications. Complications were compared for patients with complete laparoscopic procedures and in those open procedures were done. Chi-square was applied. P-value $\leqslant 0.05$ was taken as significant.

\section{Results}

During the three year period, 855 laparoscopic cholecystectomies were performed. There were 19 (2.2\%) records which were incomplete such that neither any complication was mentioned nor "no intra/postoperative complication" was mentioned. In 778 (90.9\%) records, "no intra/postoperative complication" was mentioned. Procedure-related intra/postoperative complication occurred in 58 (6.8\%) patients. All records were included for analysis.

There were 312 males (36.5\%) and 543 females (63.5\%) in the sample. Their mean age was $48 \pm 11$ years. There were 487 (56.9\%) patients of age less than 50 years and 368 (43.1\%) were older than 50 years of age. Their mean body mass index (BMI) was $29.2 \pm 4.5 \mathrm{~kg} / \mathrm{m}^{2}$. There were 429 (50.2\%) patients with BMI $\leqslant$ $29.9 \mathrm{~kg} / \mathrm{m}^{2}$ and 426 (49.8\%) patients were obese with BMI more than $29.9 \mathrm{~kg} / \mathrm{m}^{2}$. All procedures were elective and no emergency procedure was performed. There were $353(41.3 \%)$ patients identified as multi-morbid $(\geqslant 2$ chronic illnesses). The most common comorbidities were related to the cardiovascular system ( $\mathrm{n}=211$; 59.7\%), followed by metabolic ( $n=179 ; 50.7 \%)$, and renal system $(n=114 ; 32.3 \%)$.

Procedure-related complications were reported in 58 (6.8\%) patients. The frequency of occurrence of different complications is shown in table 1 . The rate of mortality was $0.2 \%$. 


\section{Cureus}

\section{Complications}

No Complications

Missing data

Complications

Intraoperative complications

Intraoperative bleeding

Bile duct injury

Ligation of CBD

Duodenal perforation

Conversion to open procedure

Postoperative complications

Surgical site infection

Jaundice

Biliary peritonitis

Intra-abdominal collections

Fecal peritonitis

Bile leakage

Death

Retained CBD stones
Frequency (\%)

778 (90.9\%)

$19(2.2 \%)$

$58(6.8 \%)$

$11(1.3 \%)$

$9(1.1 \%)$

$4(0.5 \%)$

$7(0.8 \%)$

$31(3.6 \%)$

$23(2.7 \%)$

$11(1.3 \%)$

$10(1.2 \%)$

$6(0.7 \%)$

$5(0.6 \%)$

$4(0.5 \%)$

$2(0.2 \%)$

$1(0.1 \%)$

TABLE 1: Frequency of occurrence of different complications in patients undergoing laparoscopic cholecystectomy $(n=855)$

CBD - Common Bile Duct

Patient demographic profiles were then compared with the incidence of complications. Age, multimorbidity, and obesity were significantly correlated with the incidence of complications as shown in table 2 . 


\section{Cureus}

\begin{tabular}{|c|c|c|c|}
\hline Variable & No complication $n=797$ (93.2\%) & Complications n=58 (6.8\%) & P-value \\
\hline \multicolumn{4}{|l|}{ Age } \\
\hline Less than 50 years & $463(58.1 \%)$ & $24(41.4 \%)$ & \multirow{3}{*}{0.01} \\
\hline More than 50 years & $334(41.9 \%)$ & $34(58.6 \%)$ & \\
\hline \multicolumn{3}{|l|}{ Gender } & \\
\hline Male & $289(36.3 \%)$ & $23(39.7 \%)$ & \multirow{2}{*}{0.26} \\
\hline Female & $508(63.7 \%)$ & $35(60.3 \%)$ & \\
\hline \multicolumn{4}{|l|}{ Multi-morbid patient } \\
\hline Yes & $315(39.5 \%)$ & 38 (65.5\%) & \multirow{2}{*}{0.0001} \\
\hline No & $482(60.5 \%)$ & $20(34.5 \%)$ & \\
\hline \multicolumn{4}{|l|}{ Body mass index } \\
\hline Less than $29.9 \mathrm{~kg} / \mathrm{m}^{2}$ & $411(51.5 \%)$ & $18(31.0 \%)$ & \multirow{2}{*}{0.002} \\
\hline More than $29.9 \mathrm{~kg} / \mathrm{m}^{2}$ & $386(48.4 \%)$ & 40 (69.0\% & \\
\hline
\end{tabular}

TABLE 2: Comparison of demographic characteristics of patients with and without procedurerelated complications $(n=855)$

In 31 (3.6\%) patients, laparoscopic procedure was converted to open laparotomy. In the remaining 824 (96.4\%) patients, procedures were completed laparoscopically. The incidence of intra/postoperative complications were compared for both these groups. All of the intra/postoperative complications other than intra-abdominal collections and retained common bile duct stones were statistically more significant in patients who were converted to open procedures. All of the patients who developed duodenal perforation were opened for exploratory laparotomy. The differences are shown in table 3. 


\section{Cureus}

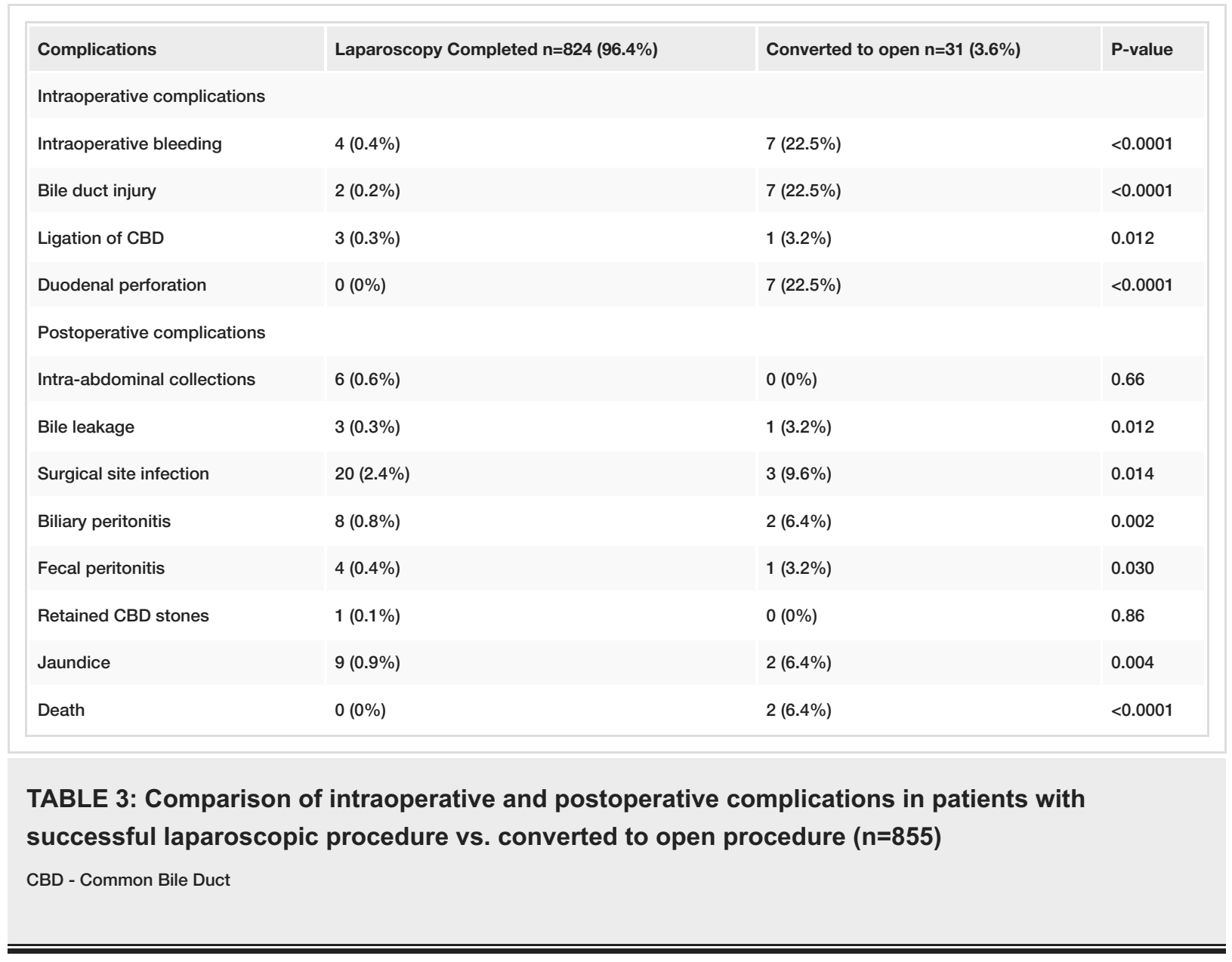

\section{Discussion}

Laparoscopic cholecystectomy has made its place as the gold standard procedure for management for gallstones. In comparison to the open procedure, it is being readily practised as a "day-surgery" procedure. However, like all other medical procedures, LC also has its complications. Some complications, which may occur due to surgeon or equipment factors, may be avoidable; however, others which are due to patient factor may be unavoidable. In this study, complications were more common in males, older patients, highrisk, and in obese patients. This study retrospectively analyzed that the rate of complications in patients undergoing elective LC for gallstones is $6.8 \%$ and only $3.6 \%$ procedures were converted to open.

This is a substantial study with a large sample and detailed analysis of intraoperative and postoperative complications. However, the study has its limitations too. The study design was retrospective and data was gathered from patient records, hence subjected to bias. Also, the differences in the duration of hospital stay between the two groups (open vs LC) could also not be included in the study due to missing data.

The need to convert a laparoscopic procedure into an open one should never be taken as a surgical failure. Instead, it is an attempt to minimize the risk of morbidity and mortality. With frequent use of LC, the rate of conversion has been dropping. This is because with time surgeons are gaining more experience in this minimally invasive technique. The literature reports the rate of conversion as 1-24\% [11-14].

In the recent literature, complications associated with LC included massive hemorrhage (0.3-1\%), bile duct injury $(0.13 \%)$, duodenal injury $(0.13 \%)$, colon injury $(0.06 \%)$, and $9.8 \%$ patients needed conversion to open procedure [15]. Similarly, in a retrospective analysis of 10 -year records, successful LC was performed in $94 \%$ patients, the postoperative morbidity rate was $1.5 \%$, and conversion to open laparotomy occurred in $3.5 \%$ patients [16]. In another Saudi study, the rate of complications associated with LC was 7.5\% with hemorrhage (35\%) and infection (22.5\%) being the most common [17]. In a nationwide large scale study, the complication rate with LC was $6.8 \%$. Patient factors - age ( $>65$ years), male gender, and higher comorbidity score - were associated with complications more frequently than surgeon or equipment related factors. Surgeon or hospital volume did not independently increase the risk of complications in their analysis [18]. In another study that compared the outcome of LC done by resident trainees and experienced surgeons, it was deduced that trainees could perform difficult LCs under careful supervision and it did not increase the risk of complications; however, trainees took a long time to complete the procedure. They reported a conversion rate of only $1.7 \%$ in their study [19]. In comparison, Indian study reported high complication rate (14\%), bile 
leakage (35.3\%) and subhepatic abscess (26.5\%) as common complications as compared to hemorrhage (11.8\%) [20] reported in most of the literature $[15,16]$. However, they did not mention the reasons behind high complication rate.

The outcome of LC majorly depends on patient factors and also surgeon and equipment factors. Like any other medical intervention, LC also has its complications. With a careful patient selection, timely medical intervention, and controlling surgeon and technical factors, LC has the potential to produce excellent results. It is the gold standard therapy for managing symptomatic gallstones.

\section{Conclusions}

The rate of complications associated with laparoscopic cholecystectomy and the rate of conversion to open laparotomy is low in this retrospective analysis conducted with patients of symptomatic gallstones. Older age, obesity, and multi-morbidity was associated with complications. Both intraoperative and postoperative complications were more common in procedures which were converted to open.

\section{Additional Information}

\section{Disclosures}

Human subjects: Consent was obtained by all participants in this study. Dr Ruth Pfau Hospital issued approval MU/ECA/19/134. Animal subjects: All authors have confirmed that this study did not involve animal subjects or tissue. Conflicts of interest: In compliance with the ICMJE uniform disclosure form, all authors declare the following: Payment/services info: All authors have declared that no financial support was received from any organization for the submitted work. Financial relationships: All authors have declared that they have no financial relationships at present or within the previous three years with any organizations that might have an interest in the submitted work. Other relationships: All authors have declared that there are no other relationships or activities that could appear to have influenced the submitted work.

\section{References}

1. The growing global burden of gallstone disease . (2016). Accessed: 11 June, 2019: http://www.worldgastroenterology.org/publications/e-wgn/e-wgn-expert-point-of-view-articlescollection/the-growing-gl....

2. Bilal M, Haseeb A, Saad M, et al.: The prevalence and risk factors of gall stone among adults in Karachi, South Pakistan: a population-based study. Glob J Health Sci. 2016, 9:106-114. 10.5539/gjhs.v9n4p106

3. Goyal V, Nagpal N, Gupta M, Kapoor R: A prospective study to predict the preoperative risk factors for conversion of laparoscopic to open cholecystectomy. J Contemp Med Surg Radiol. 2017, 2:148-152.

4. Coccolini F, Catena F, Pisano M, et al.: Open versus laparoscopic cholecystectomy in acute cholecystitis. Systematic review and meta-analysis. Int J Surg. 2015, 18:196-204. 10.1016/j.ijsu.2015.04.083

5. Vollmer CM Jr, Callery MP: Biliary injury following laparoscopic cholecystectomy: why still a problem? . Gastroenterol. 2007, 133:1039-1041.

6. Ahmed W, Iqbal M, Ahmed I: Is there any change in demographic pattern of patients with Cholelithiasis? . Isra Med J. 2017, 9:75-79.

7. Parikh SP, Szczech EC, Castillo RC, et al.: Prospective analysis of laparoscopic cholecystectomies based on postgraduate resident level. Surg Laparosc Endosc Percutan Tech. 2015, 25:487-491. 10.1097/SLE.0000000000000209

8. Dalwani AG, Shaikh R, Das K, Devrajani T, Shah ZA, Shah A: Complications of laparoscopic cholecystectomy at Liaquat University, Jamshoro. World App Sci J. 2013, 23:808-811.

9. Rashid T, Naheed A, Farooq U, Iqbal M, Barakat N: Conversion of laparoscopic cholecystectomy into open cholecystectomy: an experience in 300 cases. J Ayub Med Coll Abbottabad. 2016, 28:116-119.

10. Sakpal SV, Bindra SS, Chamberlain RS: Laparoscopic cholecystectomy conversion rates two decades later . JSLS. 2010, 14:476-483. 10.4293/108680810X12924466007926

11. Al Masri S, Shaib Y, Edelbi M, et al.: Predicting conversion from laparoscopic to open cholecystectomy: a single institution retrospective study. World J Surg. 2018, 42:2373-2382. 10.1007/s00268-018-4513-1

12. Giger UF, Michel JM, Opitz I, Inderbitzin DT, Kocher T, Krähenbühl L: Risk factors for perioperative complications in patients undergoing laparoscopic cholecystectomy: analysis of 22,953 consecutive cases from the Swiss Association of Laparoscopic and Thoracoscopic Surgery database. J Am Coll Surg. 2006, 203:723-728. 10.1016/j.jamcollsurg.2006.07.018

13. Zhang WJ, Li JM, Wu GZ, Luo KL, Dong ZT: Risk factors affecting conversion in patients undergoing laparoscopic cholecystectomy. ANZ J Surg. 2008, 78:973-976. 10.1111/j.1445-2197.2008.04714.x

14. Genc V, Sulaimanov M, Cipe G, et al.: What necessitates the conversion to open cholecystectomy? A retrospective analysis of 5164 consecutive laparoscopic operations. Clinics. 2011, 66:417-420. 10.1590/S1807-59322011000300009

15. Zaidi AH, Halim A, Azami R, Rana SH, Naqvi S, Shan A: Complications in laparoscopic cholecystectomy . Ann Punjab Med Coll. 2015, 9:57-65.

16. Tuveri M, Tuveri A: Laparoscopic cholecystectomy: complications and conversions with the 3-trocar technique: a 10-year review. Surg Laparosc Endosc Percutan Tech. 2007, 17:380-384. 10.1097/SLE.0b013e3180dca5d6

17. Nasser MF, Hussein YM, Moustafa M, et al.: Our experience of laparoscopic cholecystectomy at King Abdullah Hospital, Bisha: a retrospective study. Pak J Surg. 2015, 31:158-160. 


\section{Cureus}

18. Murphy MM, Ng SC, Simons JP, Csikesz NG, Shah SA, Tseng JF: Predictors of major complications after laparoscopic cholecystectomy: surgeon, hospital, or patient?. J Am Coll Surg. 2010, 211:73-80.

10.1016/j.jamcollsurg.2010.02.050

19. Atta HM, Mohamed AA, Sewefy AM, Abdel-Fatah AF, Mohammed MM, Atiya AM: Difficult laparoscopic cholecystectomy and trainees: predictors and results in an academic teaching hospital. Gastroenterol Res Pract. 2017, 6467814:1-5. 10.1155/2017/6467814

20. Sarda DK, Garg PK: Retrospective analysis of complications associated with laparoscopic cholecystectomy: a hospital based study. J Adv Med Dent Scie Res. 2018, 6:40-42. 